\title{
DEVELOPMENT STRATEGIES OF SELECTED CLUSTERS FROM THE ŚWIĘTOKRZYSKIE REGION
}

\author{
Agnieszka PREDYGIER \\ Department of Management, Faculty of Law and Social Sciences, Jan Kochanowski University in Kielce; \\ agnieszka.predygier@ujk.edu.pl, ORCID: 0000-0003-3283-2592
}

\begin{abstract}
Purpose: The purpose of the article was to make an attempt to determine the development opportunities of entities concentrated in specific social and economic conditions of the clusters of the Świętokrzyskie region. The entities operating in clusters are sectorally and geographically concentrated, creating inter-organisational cooperation networks using the factors of common location. Common location factors can be catalysts and inhibitors of the development of entities in clusters, thus they determine the behaviour and strategic responses of the cluster.
\end{abstract}

Design/methodology/approach: The research process used the case study method. Strategies for increasing the competitiveness of entities are created by building multilevel interorganisational relations. These ties take on the character of clusters. Entities seek new competitive opportunities in a global cooperation network and take advantage of location advantages.

Findings: Integrating into clusters creates new competitive opportunities, innovative opportunities and eliminates location defects. Scenarios for the development of clusters, together with the determinants of the competitive success of entities, will be described in the organic concept of cluster creation. The new concept of creating clusters was observed on the competitive success of the Świętokrzysko-Podkarpackie Construction Cluster INNOWATOR and Grona Targowe Kielce.

Research limitations/implications: The presented analyses and assessments are forms of conceptual reflection that will be verified in the undertaken empirical research of entities operating in the Świętokrzyskie clusters. The results of conducted research on the competitiveness of business entities operating in clusters will be presented in subsequent publications.

Practical implications: Inter-organisational relationships through cluster structures shape the competitiveness and innovation of enterprises, which plays a key role in the globalising world. Location advantages and disadvantages are factors supporting competitiveness.

Social implications: The methods of supporting and developing inter-organisational relations constitute recommendations for entities creating strategies for increasing competitiveness. The examination and assessment of the advantages and disadvantages of the location of entities is an important source of information for managers of organisations functioning in interorganisational relations. 
Originality/value: The article is practical help for managers of organisations who are looking for opportunities to increase competitiveness in building cluster structures and who want to bypass the threats arising from location factors.

Keywords: competitiveness of enterprises, clusters, clusters, inter-organisational relations.

\section{Introduction}

Ten years of cluster activity have led to a reflection upon their achievements and an assessment of these structures in terms of their development perspectives in a modern organisational cooperation strategy. Many foreign authors have made attempts to analyse their purposefulness and profitability in the economic and social sphere: J.H. von Thünen (Thünen, 1910), A. Weber (Weber, 1909), W. Lunhardt (Lunhardt, 2015), A. Predöhl (Predöhl, 1925), A. Lösch (Lösch, 1940), B. Ohlin (Ohlin, 1933), T. Palander (Palander, 1935), G. Myrdal (Myrdal, 1957), E.M. Hoover (Hoover, 1962), W. Isard (Isard, 1956) and others Many studies by foreign authorities tended to claim that cluster structures determine the increase in the competitiveness of micro-businesses and small and medium-sized enterprises. It seems that a decade of cluster operation raises such questions: What will happen with Polish clusters? Were clusters just an instrument for using European funds? What is the future of Polish clusters? What determines their development? What are the reasons for the collapse of clusters? The author of the article has made an attempt to analyse ten years of operation of two clusters in the Świętokrzyskie region, examine their chances and opportunities and determine a possible strategy and development directions. The nature of the considerations made in the article is primarily theoretical and modelling. In 2019, research was conducted to examine entities in selected clusters operating in the Świętokrzyskie region. The results of these studies will be published in subsequent articles.

\section{Scenarios of cluster development regarding advantages and disadvantages of the co-location of entities}

The characteristic features of clusters as structures limited to a certain area include the simultaneous cooperation and competition of entities operating in clusters. That is why they are particularly sensitive to location factors.

Location factors determine the formation, development, decline and closure of clusters and have been widely described in the analyses undertaken by Anna Lis (Lis, 2018). The location of economic activity in a given geographical area influences the determination of a certain development scenario, taking advantage of opportunities or eliminating threats, as it creates 
modern strategies for cluster development. The purpose of the article was to make an attempt to determine the development opportunities of entities concentrated in specific social and economic conditions of the clusters from the Świętokrzyskie region. Entities operating in clusters are concentrated in terms of their geographical location and sectors they operate in, and by creating inter-organisational cooperation networks, they use co-location factors. Co-location factors can be catalysts and inhibitors of the development of entities in clusters, and thus, they determine the behaviour and strategic responses of clusters. The advantages and disadvantages of location determine the conditions for cluster development and affect the selection of specific development alternatives of entities cooperating in the cluster. By using the concept of advantages and disadvantages of the co-location of entities, it is possible to consider the development scenarios of clusters and define a common strategy of entities concentrated in these structures in terms of their geographical location and sectors they operate in. The analyses and assessments presented herein are a form of conceptual reflections that will be verified in the undertaken empirical studies of entities operating in the clusters in the Świętokrzyskie region. The results of research on the competitiveness of economic entities operating in clusters will be presented in subsequent publications. Entities operating in clusters can benefit from the advantages of co-location. A synergistic effect can be achieved thanks to developing the activities of entities, i.e. increasing their integrative behaviours implementing a cooperation strategy. An advantage of such cooperation would be an increased importance of knowledge, transfer of knowledge to entities and development of clusters with a high intellectual potential. This activity makes it possible to use the same suppliers, negotiate prices or access to the market for highly qualified employees. Other advantages of the development of such activities of entities include social interactions, which are manifested through participation in industry associations, observing companies, monitoring competitiveness and benchmarking methods of work organisation. One of the advantages of the operation of entities in clusters is the development of local companies that take advantage of the benefits of close relationships with future customers, an increased quality strategy, as they operate for clients with significant, specific requirements and reduced costs, and the use of production economies of scale, i.e. the introduction of cost optimisation strategies. Other advantages of the location of entities in the cluster include rapid spread and promotion of knowledge and technology, a specialised labour market, as well as infrastructural and innovative benefits (learning by acting and observing others, training employees). The entities also value the obtained mobility of employees and, above all, the strong social and cultural interactions (i.e. trust, common cultural norms, customs, social bonds, sharing experience). Local companies take advantage of social trust and recommend their services to each other or create bonds of subcontracting works (e.g. in construction, catering). Applying network mechanisms makes it possible to take advantage of opportunities in the form of close relationships to suppliers, skipping transit costs, achieving economies of scale, observing competitors, the ability to use collective knowledge and social interaction. It should be noted that in addition to the advantages of co-location, there may be threats that reduce the competitive abilities of entities in clusters 
(Lis, 2018a). One of the disadvantages described by Lis is the rigid specialisation in a selected industry, which reduces the adaptability of the organisation. An analysis of the competitiveness of clusters in the aspect of the organic concept of clustering has indicated that the vast majority of location defects can be eliminated or reduced. If one takes account of the dynamics of clusters' development, it is noticed that the process of continuous admission of new cluster members, as well as the evolutionary expansion of clusters in the bands, excludes the danger of "closing" or hampering development by suppressing new ideas in the group thinking system. If the cluster includes representatives of research centres, universities, business environment organisations, the absorption of innovations to entities in clusters, as well as the creation of new trends, research, dynamization and improvement of processes, is inevitable.

Problems related to the discontinuity in technology or differences between the needs of purchasers are also eliminated, because the development of the cluster enters new sales markets and eliminates the problem of seasonality of sales and the use of supply and demand principles on a global scale. The problem of industrial districts with low development potential and without industrial culture, highly developed technology and specialised infrastructure, which seem to be a big problem, is also solved. In clusters functioning in the aspect of bands or multiclusters, the weaknesses of regions are turned into their advantages, e.g. regions with weak industrialisation may seize the opportunity and develop tourism. In the global cooperation network, local animosities disappear, and nepotism or close dependence on technocratic institutions are less common as well. Together with the open approach of a cluster to cooperate with clusters representing other industries, the threat of the inflow of unnecessary information is eliminated, the network requires continuous education of members in various industries, adjusting their own capabilities and discovering new opportunities, and network members enforce pressure on other entities related to the acquisition of new knowledge, flexibility, openness and constant formation of high intellectual and social capital. Social capital in the form of social trust and norms and assimilation of shared values does not mean "being closed in homogeneity", but on the contrary, thinking patterns are constantly torn apart and changed, and tested ways of providing solutions are improved, and reactions to new situations (culture, traditions, customs of others regions) are practiced. A natural innovation strategy is created, which shapes the ability to anticipate and respond to variable and changeable situations. Clusters operating in bands weaken local bonds for the benefit of global ties, and the dominant strategy among the associated entities is the market niche strategy, seeking "gaps", improvements, individuality and innovation. The strategy of the evolution of clusters into bands provides a chance to overcome economic problems and conflicts. 


\section{Analysis of INNOWATOR, a cluster from the Świętokrzyskie and Podkarpackie region}

The concept of a cluster as an industrial district that brings added value to its participants, as demonstrated by the experiences of Silicon Valley described by Porter, has been known for a long time (Porter, 2001). However, in Poland, clusters have gained recognition only since 2002, when a team led by Prof. Olesiński published research on the construction cluster in the Świętokrzyskie Voivodeship (Olesiński and Predygier, 2002).

Until 2004, in the Świętokrzyskie Voivodeship, there had been an informal construction cluster composed of 180 companies operating in a simple value chain relationship: raw material supplier - manufacturer of construction materials - entrepreneurs of construction products equipment manufacturers - service providers - interior finishing companies - financial environmen - accounting, marketing, training companies and the business environment.

The construction cluster in the Świętokrzyskie Voivodeship was formalised in 2010. The cluster leader was the Old Polish Chamber of Commerce and Industry in Kielce, an organisation of the business environment with 70 years of experience in building cooperation between industrial enterprises. INNOWATOR, a construction cluster from the Świętokrzyskie and Podkarpackie region, is a group of companies representing the construction industry in this region, cooperating with each other, as well as with local government units and the state administration.

The easy flow of knowledge favours increasing the competitiveness of companies associated in the cluster structure. "High mobility of employees, but first and foremost - strong social and cultural interactions: trust, shared cultural norms, shared customs and social bonds (and thus social and cultural capital) favours it. Common origin and acquired experience make it possible for the entrepreneurs associated in the cluster structure to use a common base of knowledge and share it" (Lis, 2018b, p. 134). The purpose of the cluster is to create mechanisms to obtain necessary knowledge, implement the latest technologies and exchange information between members of the construction cluster. The main assumption of a construction cluster is to facilitate communication between entities from the construction industry, exchange experiences, as well as create links between companies in order to implement larger construction projects, which is a contributing factor to increasing the competitiveness of cluster members. The construction sector in the aforementioned regions offers great development opportunities, because smaller construction companies manufacturing building components or providing services are developed around large ones. Inspiring activities aimed at simplifying administrative procedures important in investment processes and contributing to the increase of attractiveness of investment areas of regions are an added value to a construction cluster. The cluster comprises 64 companies and maintains upward trends by welcoming new members, educating employees, incubating production innovations and expanding inter-organisational relationships. 


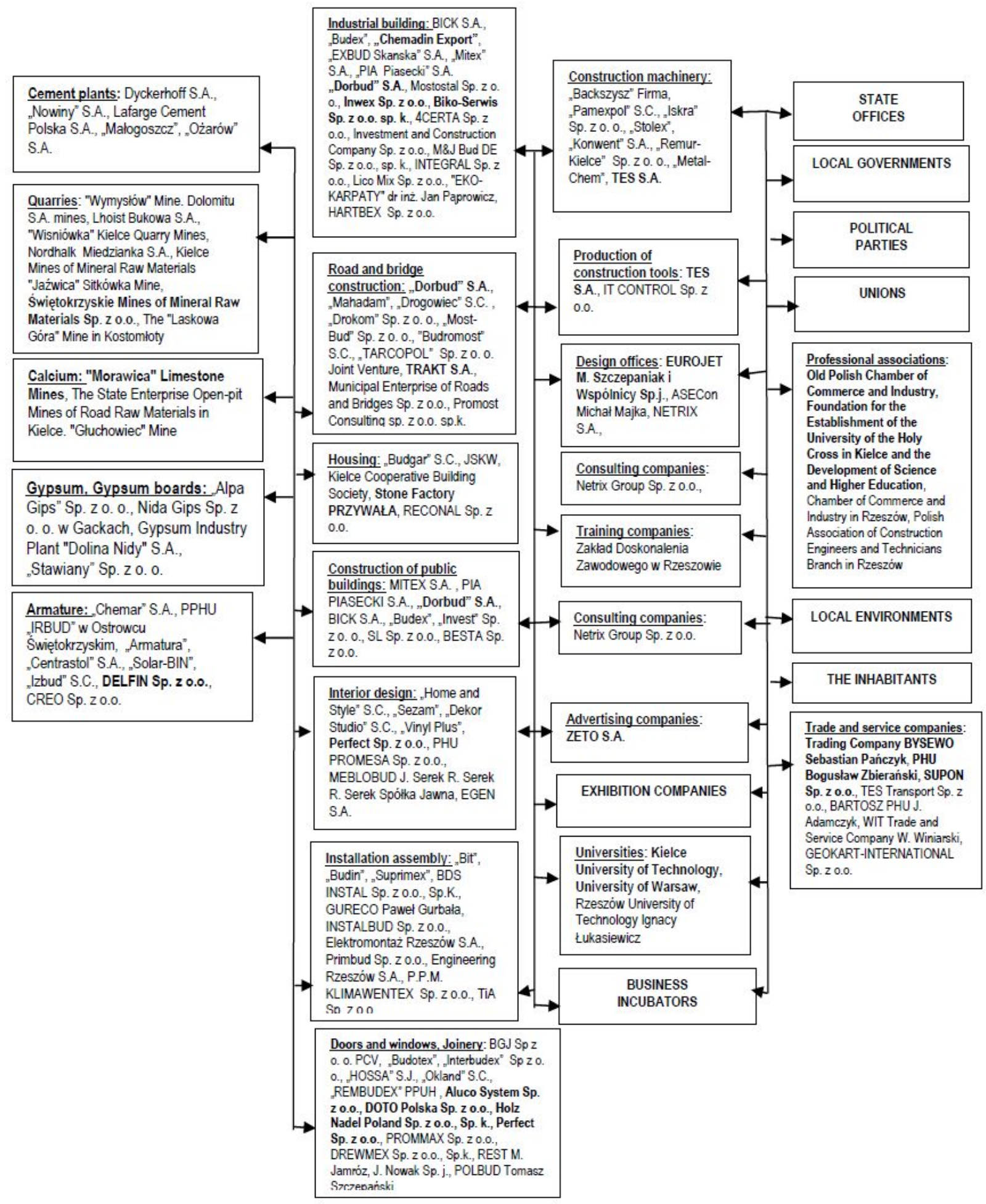

Figure 1. INNOWATOR, a construction cluster from the Świętokrzyskie and Podkarpackie region. Source: own study based on materials from the Old Polish Chamber of Commerce and Industry in Kielce, "The strategy of INNOWATOR construction cluster from the Świętokrzyskie and Podkarpackie region”, Kielce 2019. 


\section{Analysis of a trade fair cluster in Kielce}

Clusters favour creating vertical structures that can be shaped, inter alia, by cooperation with business environment organisations and science organisations. The inter-organisational relationship through cluster structures shapes the competitiveness and innovation of companies, which plays a key role in the globalising world. Development trends and growth strategies are also presented with the example of a trade fair cluster in Kielce. The figure of operation of the a trade fair cluster in Kielce can be presented in the form of a model as follows.

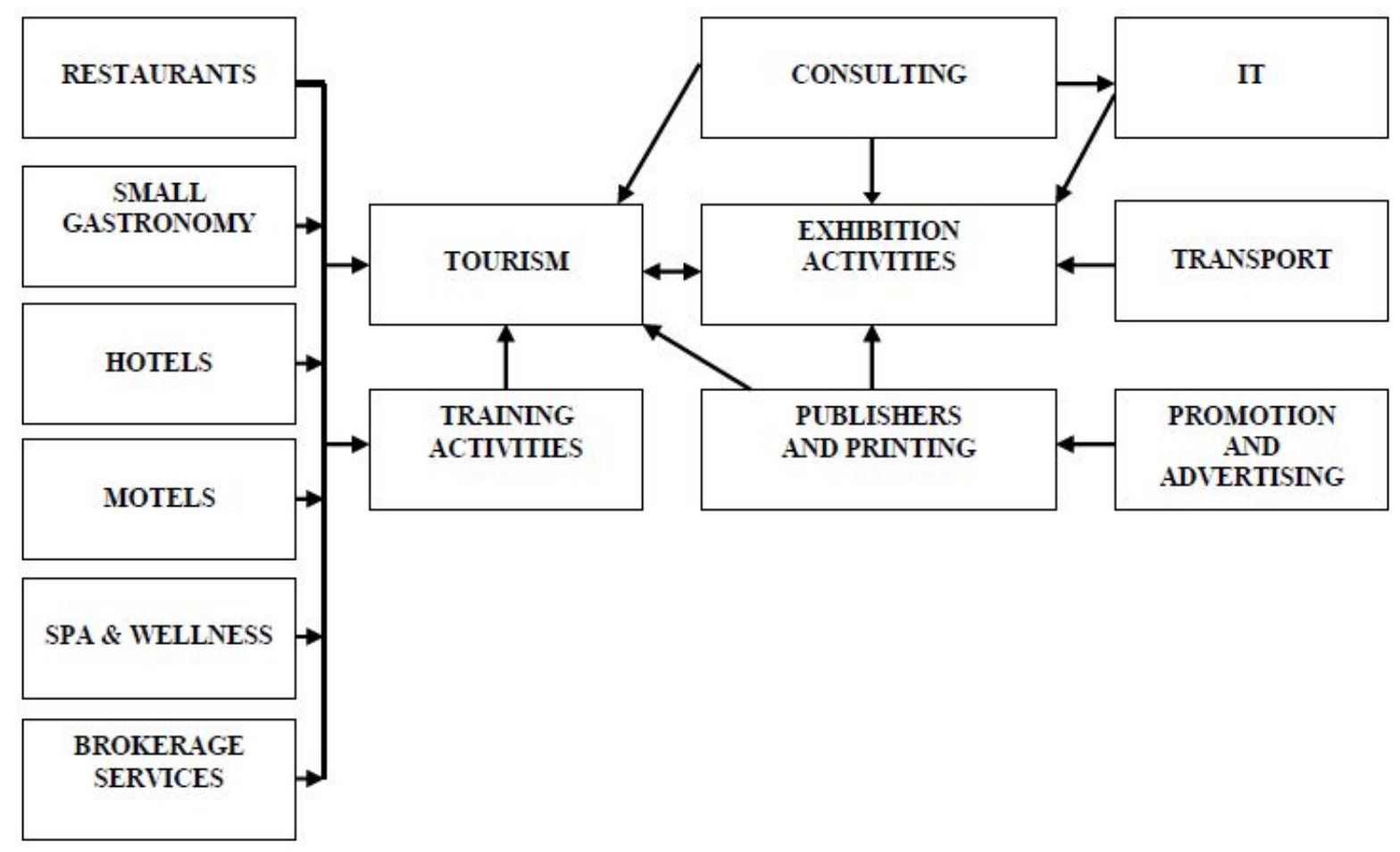

Figure 2. A model of a trade fair cluster in Kielce. Source: own study based on source materials from a trade fair cluster in Kielce, Kielce 2019.

An analysis and assessment of the presented model of the trade fair cluster in Kielce made it possible to conduct in-depth research that separated the organisations forming the cluster. The figure below completes the presented model with entities operating in the trade fair cluster in Kielce.

A trade fair and exhibition cluster is an organisation open to all entities operating in accordance with the rules adopted by the chamber's regulations and maintaining the values of business ethics. Since 2010, cluster members have been building competitive growth through a strategy of joint operations according to Targi Kielce S.A., a prestigious organisation known all over Poland, which sets the tone of strategic activities for associated organisations. The trade fair cluster in Kielce was created in 2008 (Pastuszka, 2015, p. 186). 


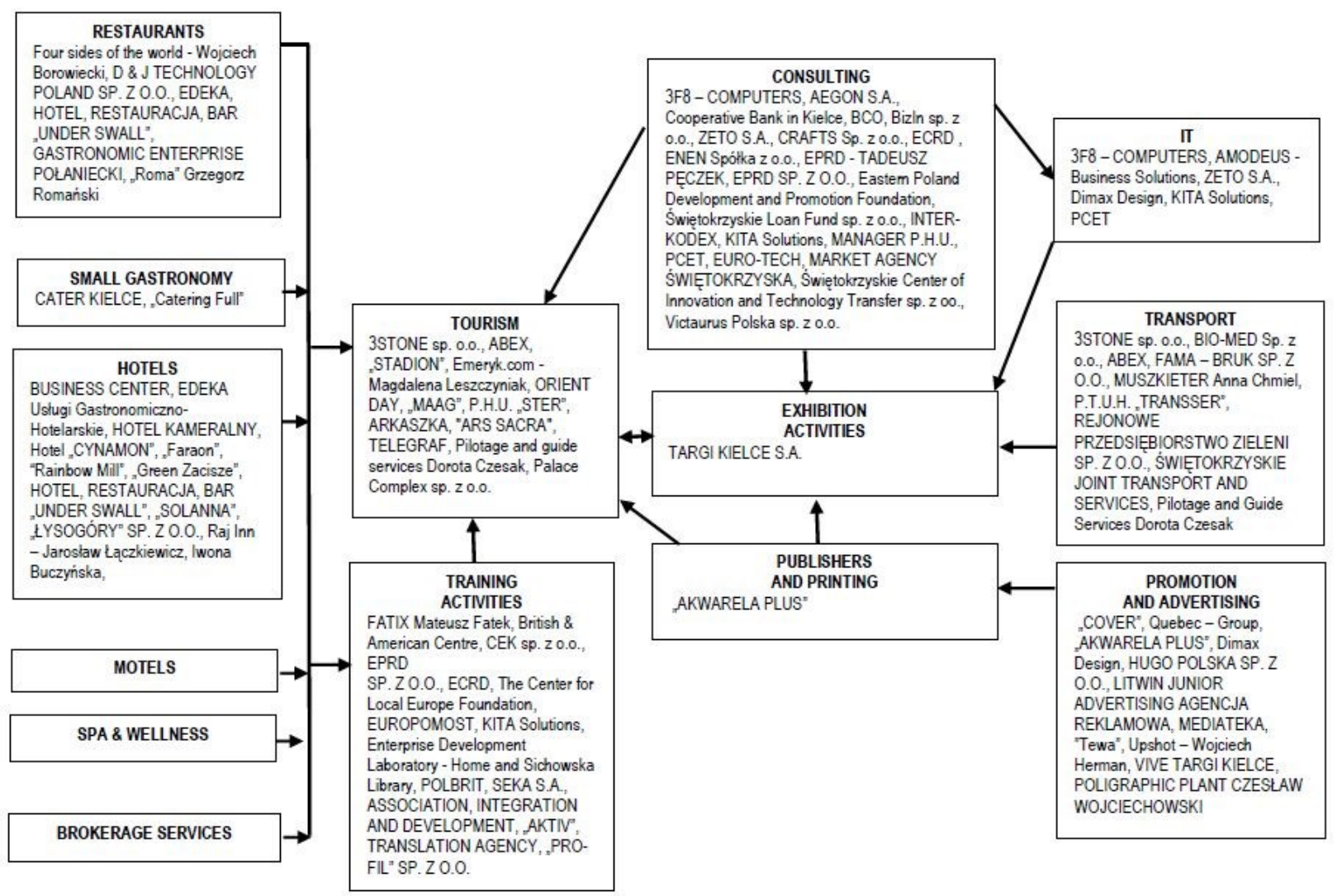

Figure 3. Entities operating within the trade fair cluster in Kielce. Source: own study.

The creation of the trade fair cluster in Kielce was preceded by an analysis of local and regional conditions on the basis of the strategy of the voivodeship, which made it possible to identify the strengths and weaknesses of the voivodeship, as well as weaknesses that constitute a significant barrier in the development of many economic sectors of the region. Due to the business nature and the scale of influence of the services, the exhibition centre: Targi Kielce Sp. z o.o. was indicated as the leading entity of the cluster. The trade fair centre in Kielce is the second largest entity in the Polish trade fair market, just behind the Poznań International Fair. The trade fair cluster in Kielce is comprised of 89 entities, i.e. institutions, associations and business-related organisations representing mainly exhibition, poly-graphic, hotel, catering and transport sectors, as well as training services operating in the field of culture, sport and promotion. The cluster strives to create an innovative cooperation network in the region (www.gronotargowe.pl/Klaster/Informacje-o-klastrze, 2019).

\section{Opportunities for increasing the competitiveness of entities in the organisational concept of creating clusters}

The diagram below presents an analysis of the trade fair cluster in Kielce with respect to the influence on the shape of relationship bands with other clusters in the Świętokrzyskie region. 
Together with the development of inter-cluster relations, the competitiveness of entities operating within them increases. At the same time, by expanding the network of interorganisational relations, the role of the synergistic effect of catalysts, i.e. the location advantages of the cluster, increases. The factors of the increase in competitiveness in the cluster are automatically absorbed by the entities forming the clusters. The network of interorganisational relations is dynamically increasing, and the synergistic cooperation effect covers more and more entities from other sectors and industries. All entities benefit from this cooperation, and as a consequence, their competitiveness increases. The development mechanism of clusters, i.e. evolutionary cluster growth, is an extremely beneficial phenomenon demonstrating the development potential of clusters. Entities operating within such clusters can experience competitive growth, implement strategic goals and increase their innovation by building multi-level inter-organisational relations. The inter-organisational cooperation of entities from several clusters forms a band (Olesiński, 2004). A band or a multi-cluster is the most developed form of inter-organisational cooperation in clusters. Organisations that form clusters in bands might gain remarkable competitive advantages that go beyond and exceed the capabilities of one cluster on the global market ${ }^{1}$.

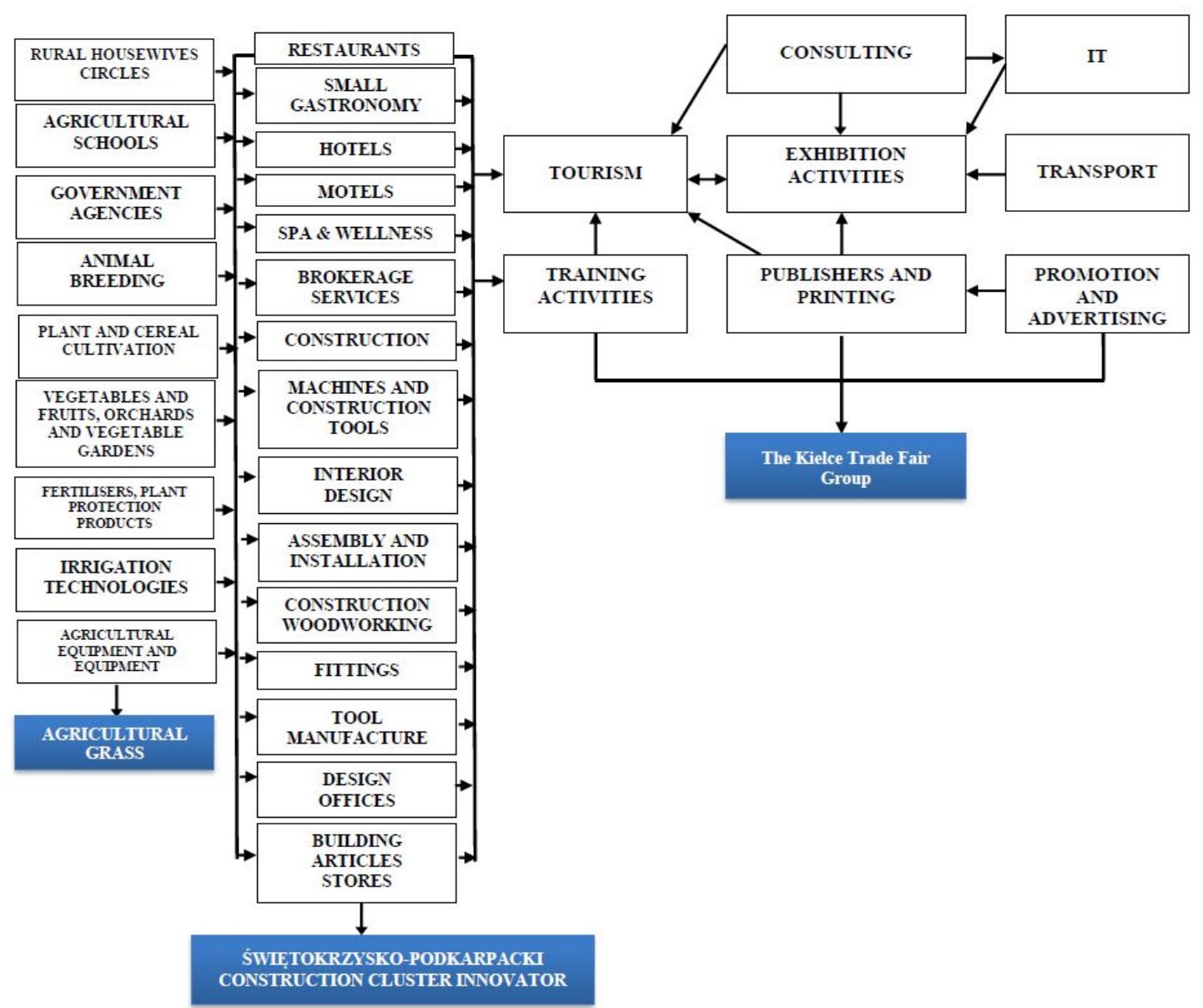

Figure 4. An organic concept of creating clusters. Source: own study on the basis of the analysis of a Californian cluster of wine producers and an Italian cluster of fashionable shoe manufacturers, M. Porter (2001). Porter o konkurencji. Warszawa: PWE.

\footnotetext{
${ }^{1}$ A band - a group of clusters established along communication lines which strongly generate synergy.
} 
The above diagram presents the phenomenon of clustering, i.e. developing clusters, which is a dynamic process of cluster expansion, development and integration of new entities within a cluster. The evolutionary process of dynamic cluster growth favours building mechanisms of connecting entities complementing the value chain from other industries. Entities operating within a cluster create multi-level relations with other organisations, which extend and go beyond the simple contact diagram: manufacturer - supplier - recipient, and are not only connected with the relations of purchasing and selling. Companies establish contacts with schools with the aim of seeking qualified staff. They also establish relationships with research centres where they jointly commercialise knowledge. Enterprises also cooperate with business organisations or universities, research organisations with the aim of building their own prestige (business club) or transfer knowledge in the educational process. Any activity of entities in the cluster generates relations with other entities that incubate innovations, generate changes in the organisation, change the strategy of conducting business, disappear or appear on the market. One entity relationship influences many subsequent relationships with customers, suppliers, producers, contractors, allies, competitors, educators, etc. As a result of the dynamics of changes in the strategy and behaviour of entity managers, these relationships grow so extensively that they extend beyond the area and industry. By entering into relationships with organisations from other industries, entities form and create new relationships (competition or cooperation) so that they establish contacts with representatives of other clusters. Therefore, entities operating in a cluster stimulate search, integration, cooperation, competition between groups - the so-called clustering. Therefore, extending a synergistic effect between clusters is an advantage of joining entities and forming clusters. The existence and development of entities in one cluster is the reason for the emergence and formation of another cluster - this phenomenon can be called clustering or developing clusters, i.e. a natural, evolutionary process of cluster development.

\section{Conclusion}

The initial analyses and assessments of the competitiveness of business entities operating in clusters in the Świętokrzyskie region included in the article were created on the basis of observations of own entities and the interviews conducted with entrepreneurs. The development of clusters is determined by the behaviour and characteristics of the entities (strategy, management styles, organisational culture, prestige, innovation) creating and forming the clusters. These peculiar, individual characteristics of entities shape clusters, ensure their development or, on the contrary, favour their fall and collapse. Therefore, it might be concluded: in order to let the clusters develop, compete and be competitive, cluster managers should pay special attention to the analysis and evaluation of characteristics, strategies and views, as well as values of entities joining or forming a cluster. 
The characteristics and strategies of the entities are therefore transferred to the clusters which are formed out of them. Entities forming clusters decide about their success or failure. Under favourable circumstances, there is a chance of clustering, i.e. a situation when a cluster expands and grows so that over time it covers entities from other industries or interreacts with the clusters that associate with them. This phenomenon can be called an organic concept of clustering, i.e. a strategy of cluster evolution. The cooperation of several clusters form a band, which is the highest level of a cluster's development and brings about the most added value to the associated entities.

The analyses and assessments made herein lead to the following conclusions regarding the future of clusters: The future of clusters depends on the potential of the entities operating within them.

\section{References}

1. Hoover, E.M. (1962). Lokalizacja działalności gospodarczej. Warszawa: PWN.

2. Information on the cluster, http://www.gronotargowe.pl/Klaster/Informacje-o-klastrze 30.05.2019.

3. Isard, W. (1956). Location and Space-economy. New York: J. Wiley and Sons.

4. Lis, A. (2018). Wspólna lokalizacja jako katalizator i inhibitor rozwoju klastrów. Studia Ekonomiczne. Zeszyty Naukowe Uniwersytetu Ekonomicznego w Katowicach, nr 351, 134.

5. Lösch, A. (1940). Die räumliche Ordnung der Wirtschaft. Jena.

6. Lunhardt, W. (2015). The Theory of the Trace: Being a Discussion of the Principles of Location. Sagwan Press, August 21.

7. Myrdal, G. (1957). Economic Theory and Underdeveloped Regions. Methuen, London: University Paperbacks.

8. Ohlin, B. (1933). Interregional and international trade. Cambridge: Harvard University Press.

9. Olesiński, Z. (2004). Proces zarządzania w sieci. In: M. Romanowska, M. Trocki (eds.), Podejście procesowe w zarządzaniu, Warszawa: Szkoła Główna Handlowa.

10. Olesiński, Z., Predygier, A. (2002). Identyfikacja i analiza grona na przykładzie grona budowlanego województwa świętokrzyskiego. Organizacja i Kierowanie, no. 3.

11. Palander, T. (1935). Beiträge zur Standortstheorie. Upsala: Dissertation Stockholm.

12. Pastuszka, S. (2015). Wpływ klastra „Grono Targowe Kielce” na rozwój województwa świętokrzyskiego. Optimum. Studia Ekonomiczne, no. 2(74), p. 186.

13. Porter, M.E. (2001). Porter o konkurencji. Warszawa: PWE.

14. Predöhl, A. (1925). Das Standortsproblem in der Wirtschaftswissenschaft. Weltwirtschaftliches Archiv, vol. XXI. 
15. Von Thünen, J.H. (1910). Der isolierte Staat in Beziehung auf Landwirtschaft und Nationalökonomie. Jena: Wydawnictwo G. Fischer.

16. Weber, A. (1909). Über den Standort der Industrien. Tübingen: Reine Theorie des Standorts. 